\title{
HER2 protein overexpression in estrogen receptor-positive ductal carcinoma in situ of the breast: frequency and implications for tamoxifen therapy
}

\author{
Laura C Collins and Stuart J Schnitt \\ Department of Pathology, Beth Israel Deaconess Medical Center and Harvard Medical School, Boston, \\ $M A, U S A$
}

\begin{abstract}
Recent clinical data have suggested that the efficacy of tamoxifen in reducing the risk of local recurrence following lumpectomy and radiation therapy in patients with ductal carcinoma in situ (DCIS) is limited to patients with estrogen receptor (ER)-positive lesions. However, it is currently not known if HER2 protein overexpression might be associated with reduced tamoxifen benefit in patients with ER-positive DCIS, as has been suggested in patients with ER-positive invasive breast cancer and in preclinical models. Moreover, the frequency of HER2 overexpression in ER-positive ductal carcinoma in situ has not been previously evaluated in detail. To address this issue, we studied ER expression and HER2 overexpression in 148 cases of DCIS using a sensitive double immunostaining technique and assessed the frequency of ER expression and HER2 overexpression in relation to each other and in relation to DCIS grade. Overall, ER expression was seen in 114 cases $(77 \%)$ and HER2 protein overexpression was seen in 42 cases (28\%). Of 114 ER-positive ductal carcinoma in situ, $14(12 \%)$ showed concurrent HER2 protein overexpression, and all 14 of these DCIS lesions were of high nuclear grade. In addition, in all 14 ER-positive DCIS cases that showed HER2 overexpression, double immunostaining demonstrated that ER and HER2 protein were coexpressed by the same neoplastic cells. We conclude that a subset of ER-positive DCIS show concomitant overexpression of HER2 protein. Whether or not HER2 overexpression is associated with a diminished response to tamoxifen in patients with ER-positive DCIS will require investigation in clinical outcome studies.
\end{abstract}

Modern Pathology (2005) 18, 615-620, advance online publication, 14 January 2005; doi:10.1038/modpathol.3800360

Keywords: estrogen receptor; HER2 protein; ductal carcinoma in situ

The expression of biological markers in ductal carcinoma in situ (DCIS), including hormone receptors, oncogenes, tumor suppressor genes and markers of cell proliferation and angiogenesis, has been an area of active investigation for the past two decades. $^{1-5}$ Studies addressing this subject have identified important correlations between the expression of various biomarkers and certain histopathologic features of DCIS, and have served to emphasize the heterogeneous nature of these lesions with regard to their biological characteristics.

Estrogen receptor (ER) and HER2 have arguably been the most widely studied biomarkers in DCIS.

Correspondence: Dr LC Collins, MD, Department of Pathology, Beth Israel Deaconess Medical Center, 330 Brookline Avenue, Boston, MA 02215, USA.

E-mail: lcollins@bidmc.harvard.edu

Received 29 September 2004; revised 18 November 2004; accepted 19 November 2004; published online 14 January 2005
Prior investigators have demonstrated that ER expression is seen in approximately $75 \%$ of DCIS cases and that the frequency of ER expression varies with the degree of differentiation, being most common in low grade and least common in high grade lesions. ${ }^{1,6-26}$ HER2 protein overexpression has been reported in approximately $40 \%$ of DCIS, and in most studies is significantly more common in lesions of high-grade than in low-grade lesions. ${ }^{1,10,12-21,23-44}$

Until fairly recently, information regarding biomarker expression in DCIS was largely of academic interest, since the presence or absence of expression of any of these markers did not impact upon patient management decisions. However, in December 2002, Allred et $a l^{45}$ presented the results of a study assessing the relationship between ER expression in DCIS and local recurrence in patients who had been treated by lumpectomy and radiation therapy, with or without tamoxifen. In that study of a subset 
of patients enrolled in the NSABP-B24 randomized clinical trial, a significant reduction of local recurrences with the use of tamoxifen was observed only in patients whose DCIS was ER-positive. ${ }^{45}$ As a result of this observation, many clinicians have begun to take the ER status of DCIS into consideration in formulating treatment recommendations and are offering adjuvant tamoxifen only to women with ER-positive DCIS. However, whether or not all patients with ER-positive DCIS will receive an equivalent level of benefit from tamoxifen remains an unresolved issue. In particular, it is not known if the simultaneous presence of HER2 overexpression might limit or negate the beneficial effects of tamoxifen in ER-positive DCIS, as has been suggested in some clinical studies of patients with invasive breast cancer and in preclinical models. ${ }^{46-54}$ Given this potential concern, and given the increasing use of tamoxifen in women with DCIS, an understanding of the frequency of HER2 overexpression in ER-positive DCIS assumes clinical importance.

While studies of patients with DCIS have generally shown an inverse relationship between ER expression and HER2 overexpression, ${ }^{10,23,24,35}$ details of the relationship between ER and HER2 expression in individual examples of DCIS has previously received little attention. The purpose of this study, therefore, was to assess the frequency of ER expression and HER2 overexpression in DCIS in relation to each other and in relation to DCIS grade, and to determine the frequency and histologic correlates of HER2 overexpression in ER-positive DCIS.

\section{Materials and methods}

The study population consisted of 148 cases of DCIS accessioned at Beth Israel Deaconess Medical Center between May 2000 and December 2003 in which there was sufficient DCIS remaining for immunostaining and for which paraffin blocks were available. For each case, all available hematoxylin and eosinstained sections were reviewed to determine the DCIS nuclear grade and to select a representative block for immunostaining. DCIS lesions were classified as low, intermediate or high nuclear grade using the criteria of Lagios. ${ }^{55}$

We performed double immunohistochemical staining for ER and HER2 using the Envision Double Stain System (DakoCytomation, Carpinteria, CA, USA) on $5-\mu \mathrm{m}$ paraffin sections cut from one representative block for each case. Sections were mounted on charged glass slides and baked at 58$60^{\circ} \mathrm{C}$ for $2 \mathrm{~h}$. Slides were allowed to cool to room temperature and were then deparaffinized in xylene and rehydrated through graded alcohols to distilled water. Subsequently, sections were subjected to heat-induced epitope retrieval (HIER) in citrate buffer, pH 6.1 (DakoCytomation Target Retrieval solution) by heating in a vegetable steamer for $40 \mathrm{~min}$ followed by cooling for $20 \mathrm{~min}$ at room temperature. Following HIER, endogenous peroxidase activity was blocked with $1 \%$ hydrogen peroxide in methanol for $10 \mathrm{~min}$. The anti-ER primary monoclonal antibody (clone 1D5, DakoCytomation, 1:50 dilution) was then applied to the sections for $30 \mathrm{~min}$ at room temperature, followed by incubation with horseradish peroxidase-labeled polymer and then with an enzyme substrate system that employs 3,3'-diaminobenzidine as the chromogen. The tissue was then treated with Doublestain Blocking Reagent (DakoCytomation) to prevent crossreactivity between the reactions and to block endogenous alkaline phosphatase activity. The antiHER2 primary antibody (rabbit polyclonal antiHER2 antibody A0485, DakoCytomation, 1:800 dilution) was applied for $30 \mathrm{~min}$ at room temperature followed by incubation with alkaline phosphatase-labeled polymer. The reaction was then completed with a substrate system using Permanent Red (DakoCytomation) as the chromogen. Tissue sections were then lightly counterstained with Mayer's hematoxylin. Two positive controls, one consisting of an invasive breast cancer known to express ER and another consisting of an invasive breast cancer known to show HER2 protein overexpression were included in each staining run. Negative controls in which the primary anti-ER and anti-HER2 antibodies were replaced by phosphate-buffered saline were performed for each case.

Each double-immunostained slide was evaluated for the presence of ER expression and HER2 protein overexpression in the DCIS cells. Tumor cells that showed nuclear staining for ER were considered ERpositive. Of note, all ER-positive cases showed staining in at least $10 \%$ of the DCIS tumor cell nuclei, whereas all ER-negative cases showed complete absence of tumor cell staining for ER (but with staining of normal breast epithelial cell nuclei). Tumor cells were considered positive for HER2 protein overexpression when greater than $10 \%$ of the cells showed strong membrane staining (equivalent to a score of $3+$ in the DakoCytomation HercepTest). ER expression and HER2 overexpression were related to DCIS nuclear grade and the frequency of expression according to nuclear grade was evaluated statistically using Fisher's exact test.

The study was approved by the Beth Israel Deaconess Medical Center Committee on Clinical Investigations.

\section{Results}

Among the 148 DCIS cases we evaluated, 18 (12\%) were low nuclear grade, $56(38 \%)$ were intermediate nuclear grade and $74(50 \%)$ were high nuclear grade. Overall, 114 cases $(77 \%)$ were ER-positive and 42 $(28 \%)$ showed HER2 overexpression. 
The relationships between ER expression, HER2 overexpression and DCIS grade are shown in Table 1. All 74 low and intermediate nuclear grade DCIS were ER-positive, whereas ER-positivity was seen in only 40 high-grade lesions (54\%). In contrast, HER2protein overexpression was seen exclusively in high-grade lesions. Thus, ER expression was significantly more common in non-high-grade than in high-grade lesions $(P<0.001)$ and HER2 overexpression was significantly more common in high-grade than in non-high-grade lesions $(P<0.001)$.

Overall, 100 cases $(68 \%)$ were ER +/HER2-, 28 $(19 \%)$ were ER-/HER2 +, six $(4 \%)$ cases were

Table 1 ER-expression and HER2 protein overexpression according to DCIS grade

\begin{tabular}{lccc}
\hline \multirow{2}{*}{ DCIS grade } & Number of cases & \multicolumn{2}{c}{ Number (\%) } \\
\cline { 3 - 4 } & & ER-positive & HER2-positive \\
\hline Low & 18 & $18(100 \%)$ & 0 \\
Intermediate & 56 & $56(100 \%)$ & 0 \\
High & 74 & $40(54 \%)$ & $42(57 \%)$ \\
\hline
\end{tabular}
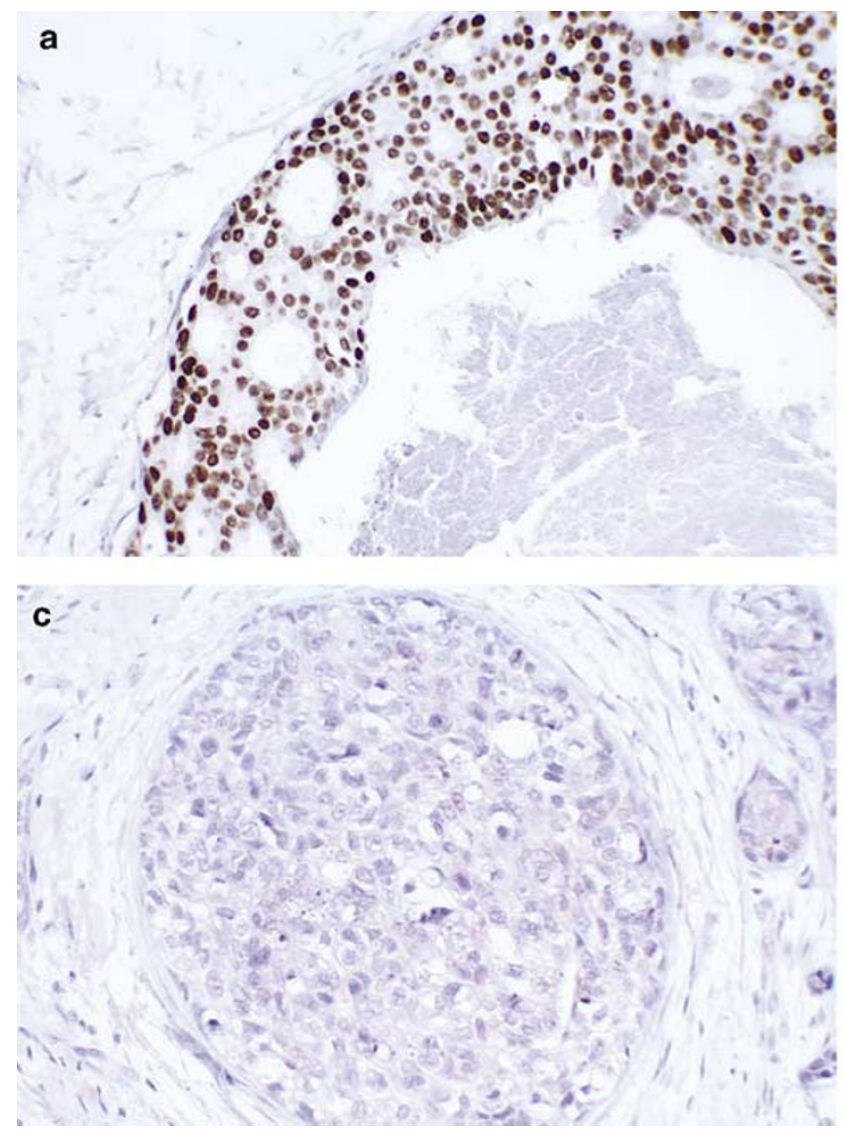

ER-/HER2-, and 14 (9\%) were ER+/HER2 + (Figure 1 and Table 2). Thus, ER expression and HER2 overexpression were reciprocally related in 128 cases $(86 \%)$. The patterns of ER-expression and HER2 overexpression according to DCIS grade are presented in Table 2. All 74 low and intermediate nuclear grade DCIS were ER + /HER2-. In contrast, the high-grade DCIS lesions were more heterogeneous with regard to patterns of ER and HER2 expression. Among the high-grade lesions, 26 (35\%) were ER +/HER2-, 6 (8\%) were ER-/HER2-, 28 $(38 \%)$ were ER-/HER2 + , and $14(19 \%)$ cases were ER + /HER2 + . Thus, coexpression of ER and HER2 was seen only in high-grade DCIS and such cases accounted for $19 \%$ of that population.

Of particular interest, among the 114 cases of ERpositive DCIS, 14 (12\%) showed concomitant HER2 overexpression. All 14 of these lesions were of high nuclear grade. HER2 overexpression was diffuse in these cases, with strong membrane staining present in all DCIS cells. However, the extent of ER expression in these 14 cases was more variable. In two of these cases, ER expression was present in the nuclei of nearly all of the HER2-positive DCIS cells. In the remainder of these cases, the proportion of DCIS cell nuclei expressing ER was between 10 and
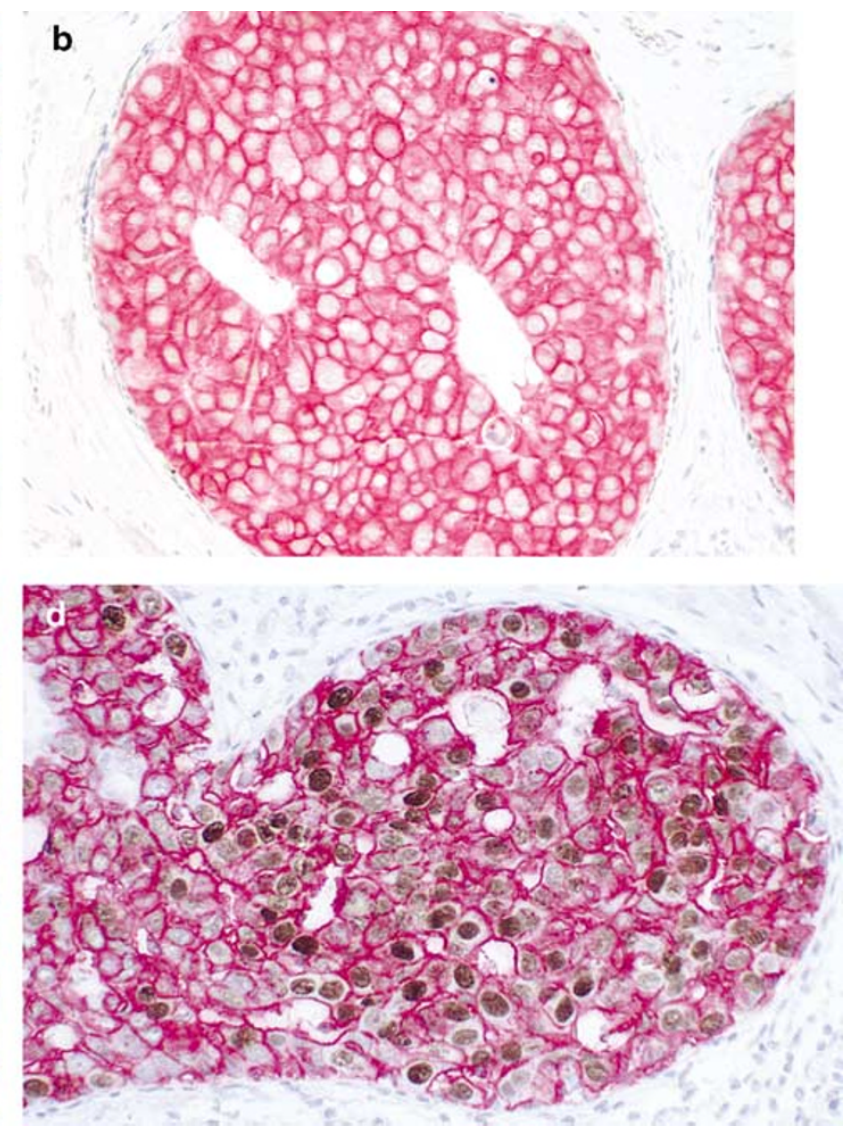

Figure 1 Examples of DCIS double immunostained for ER and HER2 protein. ER expression is denoted by brown nuclear staining and HER2 overexpression is represented by red staining of the cell membrane. (a) ER-positive/HER2-negative; (b) ER-negative/HER2-positive; (c) ER-negative/HER2-negative; (d) ER-positive/HER2-positive. 
Table 2 Patterns of ER expression and HER2 overexpression according to DCIS grade

\begin{tabular}{|c|c|c|c|c|c|}
\hline DCIS grade & Number of cases & ER+/HER2- & ER-/HER2- & ER-/HER2+ & ER+/HER2+ \\
\hline Low & 18 & 18 & 0 & 0 & 0 \\
\hline Intermediate & 56 & 56 & 0 & 0 & 0 \\
\hline High & 74 & 26 & 6 & 28 & 14 \\
\hline TOTAL & 148 & $100(67.6 \%)$ & $6(4.1 \%)$ & $28(18.9 \%)$ & $14(9.5 \%)$ \\
\hline
\end{tabular}

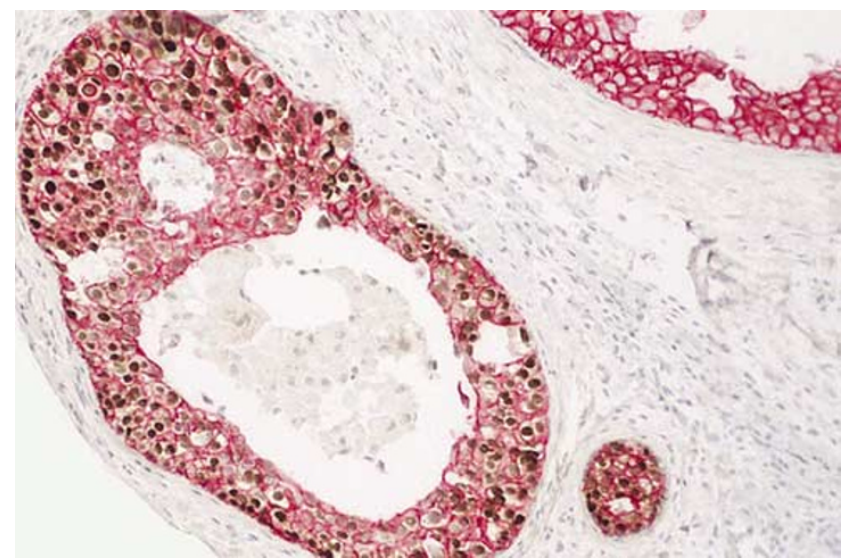

Figure 2 ER-positive/HER2-positive DCIS. In this case, some of the spaces contain DCIS cells that exhibit both ER expression and HER2 overexpression, whereas others (eg upper right) contain cells that show only HER2 overexpression.

$50 \%$. In one case, some of the ductal-lobular spaces contained HER2 + /ER + cells, whereas the DCIS cells in other spaces showed HER2 overexpression without ER expression (Figure 2). We did not identify any subpopulations of DCIS cells within any of the ER + /HER2 + cases that were positive for ER, but which lacked HER2 overexpression.

\section{Discussion}

Numerous prior studies have assessed expression of ER and/or HER2 in DCIS, and have related the expression of these markers to various histopathologic features of the lesion. In keeping with the results of many of these previous studies, we found significant relationships between ER expression and non-high-grade DCIS lesions, and between HER2 overexpression and high-grade lesions. ${ }^{1,6-44,56} \mathrm{We}$ also found, as have others, an inverse relationship between ER expression and HER2 overexpression in most cases of DCIS. ${ }^{10,23,24,35}$

However, to our knowledge, ours is the first study to utilize double immunostaining to assess ER expression and HER2 overexpression in relation to each other within individual cases of DCIS. Our results indicate that overall, approximately $10 \%$ of the DCIS cases we studied showed simultaneous ER expression and HER2 overexpression. Moreover, we found that among cases of ER-positive DCIS,
$12 \%$ showed concomitant HER2 protein overexpression. This phenomenon was restricted to DCIS lesions of high nuclear grade, and in these cases coexpression of ER and HER2 was seen in the same neoplastic cells. Only one prior study has reported upon the frequency of HER2 overexpression in ERpositive DCIS. In that study of 219 cases, Claus et $a l,{ }^{23}$ using separate immunostains for ER and HER2, found that $19 \%$ of ER-positive DCIS also showed HER2 overexpression. Further details about these cases are not provided. It is difficult to compare the results of our study with those of Claus et al ${ }^{23}$ due to methodological differences in the ER and HER2 immunohistochemical assays employed in these two studies. However, taken together, the results of these two studies suggest that approximately 10$20 \%$ of ER-positive DCIS show concomitant HER2 overexpression.

Data from several clinical studies of patients with invasive breast cancer as well as from preclinical models have suggested that HER2 protein overexpression reduces the efficacy of tamoxifen in ERpositive breast cancer, ${ }^{46-54}$ although this remains a matter of debate. ${ }^{48,57,58}$ Preliminary data from the NSABP B-24 trial have suggested that tamoxifen is effective in reducing the risk of ipsilateral breast tumor recurrence only in patients whose DCIS is ERpositive. ${ }^{45}$ However, there are currently no data available from that trial or from any other clinical study to address the question of whether or not concurrent HER2 overexpression might mitigate the effects of tamoxifen in ER-positive DCIS. Nevertheless, given our observations and given the recent trend toward the use of tamoxifen in patients with DCIS, our findings are of potential clinical importance.

It could be argued that the proportion of cases of ER-positive DCIS that also show HER2 overexpression is too small to be clinically meaningful. However, it is useful to examine this issue in absolute terms to gauge the potential clinical impact of our findings. It has been estimated that there will be approximately 216000 new female breast cancers in 2004, ${ }^{59}$ and that approximately $20 \%$ of these (43 200) will be DCIS. If $80 \%$ of these DCIS cases are ER-positive, and if, as our data suggest, $12 \%$ of those cases show concurrent HER2 overexpression, then approximately 4100 cases of DCIS diagnosed in 2004 will show the ER + /HER2 + phenotype. Therefore, whether or not to recommend adjuvant tamoxifen in patients with ER-positive DCIS because of the 
presence of simultaneous HER2 overexpression could potentially be an issue for over 4000 women each year.

In conclusion, the results of this study indicate that a subset of ER-positive DCIS cases show simultaneous HER2 protein overexpression. While this observation could have important clinical implications regarding the use of adjuvant tamoxifen in women with ER-positive DCIS, the interactions among ER expression, HER2 overexpression and response to tamoxifen will need to be evaluated in clinical outcome studies.

\section{Acknowledgements}

We thank Natasha Pliss for performing the immunohistochemical stains for this study. This work was supported in part by NIH 1 P50 CA89393-01: Dana Farber/Harvard Cancer Center SPORE in Breast Cancer.

\section{References}

1 Allred D. Biologic characteristics of ductal carcinoma in situ. In: Silverstein M (ed). Ductal Carcinoma In Situ of the Breast, 2nd edn. Lippincott Williams \& Wilkins: Philadelphia, PA, 2002, pp 37-48.

2 Ravdin PM. Prognostic factors in ductal carcinoma in situ. In: Silverstein MJ (ed). Ductal Carcinoma In Situ of the Breast, 2nd edn. Lippincott Williams \& Wilkins: Philadelphia, PA, 2002, pp 49-53.

3 Schnitt SJ. Angiogenesis in ductal carcinoma in situ of the breast. In: Silverstein MJ (ed). Ductal Carcinoma In Situ of the Breast. Lippincott Williams \& Wilkins: Philadelphia, PA, 2002, pp 234-239.

4 Burstein HJ, Polyak K, Wong JS, et al. Ductal carcinoma in situ of the breast. N Engl J Med 2004;350:1430-1441.

5 Leonard GD, Swain SM. Ductal carcinoma in situ, complexities and challenges. J Natl Cancer Inst 2004; 96:906-920.

6 Giri DD, Dundas SA, Nottingham JF, et al. Oestrogen receptors in benign epithelial lesions and intraduct carcinomas of the breast: an immunohistological study. Histopathology 1989;15:575-584.

7 Barnes R, Masood S. Potential value of hormone receptor assay in carcinoma in situ of breast. Am J Clin Pathol 1990;94:533-537.

8 Pallis L, Wilking N, Cedermark B, et al. Receptors for estrogen and progesterone in breast carcinoma in situ. Anticancer Res 1992;12:2113-2115.

9 Bur ME, Zimarowski MJ, Schnitt SJ, et al. Estrogen receptor immunohistochemistry in carcinoma in situ of the breast. Cancer 1992;69:1174-1181.

10 Poller DN, Snead DR, Roberts EC, et al. Oestrogen receptor expression in ductal carcinoma in situ of the breast: relationship to flow cytometric analysis of DNA and expression of the c-erbB-2 oncoprotein. Br J Cancer 1993;68:156-161.

11 Chaudhuri B, Crist KA, Mucci S, et al. Distribution of estrogen receptor in ductal carcinoma in situ of the breast. Surgery 1993;113:134-137.
12 Wilbur DC, Barrows GH. Estrogen and progesterone receptor and c-erbB-2 oncoprotein analysis in pure in situ breast carcinoma: an immunohistochemical study. Mod Pathol 1993;6:114-120.

13 Zafrani B, Leroyer A, Fourquet A, et al. Mammographically detected ductal in situ carcinoma of the breast analyzed with a new classification. A study of 127 cases: correlation with estrogen and progesterone receptors, p53 and c-erbB-2 proteins, and proliferative activity. Semin Diagn Pathol 1994;11:208-214.

14 Leal CB, Schmitt FC, Bento MJ, et al. Ductal carcinoma in situ of the breast. Histologic categorization and its relationship to ploidy and immunohistochemical expression of hormone receptors, p53, and c-erbB-2 protein. Cancer 1995;75:2123-2131.

15 Bose S, Lesser ML, Norton L, et al. Immunophenotype of intraductal carcinoma. Arch Pathol Lab Med 1996; 120:81-85.

16 Karayiannakis AJ, Bastounis EA, Chatzigianni EB, et al. Immunohistochemical detection of oestrogen receptors in ductal carcinoma in situ of the breast. Eur J Surg Oncol 1996;22:578-582.

17 Moreno A, Lloveras B, Figueras A, et al. Ductal carcinoma in situ of the breast: correlation between histologic classifications and biologic markers. Mod Pathol 1997;10:1088-1092.

18 Rudas M, Neumayer R, Gnant MF, et al. p53 protein expression, cell proliferation and steroid hormone receptors in ductal and lobular in situ carcinomas of the breast. Eur J Cancer 1997;33:39-44.

19 Quinn CM, Ostrowski JL, Harkins L, et al. Loss of bcl-2 expression in ductal carcinoma in situ of the breast relates to poor histological differentiation and to expression of p53 and c-erbB-2 proteins. Histopathology 1998;33:531-536.

20 Albonico G, Querzoli P, Ferretti S, et al. Biological profile of in situ breast cancer investigated by immunohistochemical technique. Cancer Detect Prev 1998;22:313-318.

21 Bhoola S, DeRose PB, Cohen C. Ductal carcinoma in situ of the breast: frequency of biomarkers according to histologic type. Appl Immunohistochem Mol Morphol 1999;7:108-115.

22 Shoker BS, Jarvis C, Sibson DR, et al. Oestrogen receptor expression in the normal and pre-cancerous breast. J Pathol 1999;188:237-244.

23 Claus EB, Chu P, Howe CL, et al. Pathobiologic findings in DCIS of the breast: morphologic features, angiogenesis, HER-2/neu and hormone receptors. Exp Mol Pathol 2001;70:303-316.

24 Ringberg A, Anagnostaki L, Anderson H, et al. Cell biological factors in ductal carcinoma in situ (DCIS) of the breast-relationship to ipsilateral local recurrence and histopathological characteristics. Eur J Cancer 2001;37:1514-1522.

25 Provenzano E, Hopper JL, Giles GG, et al. Biological markers that predict clinical recurrence in ductal carcinoma in situ of the breast. Eur J Cancer 2003; 39:622-630.

26 Rodrigues NA, Dillon D, Carter D, et al. Differences in the pathologic and molecular features of intraductal breast carcinoma between younger and older women. Cancer 2003;97:1393-1403.

27 Barnes DM, Lammie GA, Millis RR, et al. An immunohistochemical evaluation of c-erbB-2 expression in human breast carcinoma. Br J Cancer 1988; 58:448-452. 
28 van de Vijver MJ, Peterse JL, Mooi WJ, et al. Neuprotein overexpression in breast cancer. Association with comedo- type ductal carcinoma in situ and limited prognostic value in stage II breast cancer. N Engl J Med 1988;319:1239-1245.

29 Bartkova J, Barnes DM, Millis RR, et al. Immunohistochemical demonstration of c-erbB-2 protein in mammary ductal carcinoma in situ. Hum Pathol 1990; 21:1164-1167.

30 Lodato RF, Maguire Jr HC, Greene MI, et al. Immunohistochemical evaluation of c-erbB-2 oncogene expression in ductal carcinoma in situ and atypical ductal hyperplasia of the breast. Mod Pathol 1990;3:449-454.

31 Ramachandra S, Machin L, Ashley S, et al. Immunohistochemical distribution of c-erbB-2 in in situ breast carcinoma-a detailed morphological analysis. J Pathol 1990;161:7-14.

32 Barnes DM, Bartkova J, Camplejohn RS, et al. Overexpression of the c-erbB-2 oncoprotein: why does this occur more frequently in ductal carcinoma in situ than in invasive mammary carcinoma and is this of prognostic significance? Eur J Cancer 1992;28: 644-648.

33 Schimmelpenning $\mathrm{H}$, Eriksson ET, Pallis L, et al. Immunohistochemical c-erbB-2 protooncogene expression and nuclear DNA content in human mammary carcinoma in situ. Am J Clin Pathol 1992;97:S48-52.

34 Somerville JE, Clarke LA, Biggart JD. c-erbB-2 overexpression and histological type of in situ and invasive breast carcinoma. J Clin Pathol 1992;45:16-20.

35 Allred DC, Clark GM, Molina R, et al. Overexpression of HER-2/neu and its relationship with other prognostic factors change during the progression of in situ to invasive breast cancer. Hum Pathol 1992;23:974-979.

36 Tsuda H, Iwaya K, Fukutomi T, et al. p53 mutations and c-erbB-2 amplification in intraductal and invasive breast carcinomas of high histologic grade. Jpn J Cancer Res 1993;84:394-401.

37 Bobrow LG, Happerfield LC, Gregory WM, et al. The classification of ductal carcinoma in situ and its association with biological markers. Semin Diagn Pathol 1994;11:199-207.

38 De Potter CR, Schelfhout AM, Verbeeck P, et al. neu overexpression correlates with extent of disease in large cell ductal carcinoma in situ of the breast. Hum Pathol 1995;26:601-606.

39 Mack L, Kerkvliet N, Doig G, et al. Relationship of a new histological categorization of ductal carcinoma in situ of the breast with size and the immunohistochemical expression of p53, c-erb B2, bcl-2, and ki-67. Hum Pathol 1997;28:974-979.

40 Kanthan R, Xiang J, Magliocco AM. p53, ErbB2, and TAG-72 expression in the spectrum of ductal carcinoma in situ of the breast classified by the Van Nuys system. Arch Pathol Lab Med 2000;124:234-239.

41 Ho GH, Calvano JE, Bisogna M, et al. In microdissected ductal carcinoma in situ, HER-2/neu amplification, but not p53 mutation, is associated with high nuclear grade and comedo histology. Cancer 2000;89:21532160.

42 Ottesen GL, Christensen IJ, Larsen JK, et al. Carcinoma in situ of the breast: correlation of histopathology to immunohistochemical markers and DNA ploidy. Breast Cancer Res Treat 2000;60:219-226.

43 DiGiovanna MP, Chu P, Davison TL, et al. Active signaling by HER-2/neu in a subpopulation of HER-2/neu-overexpressing ductal carcinoma in situ: clinicopathological correlates. Cancer Res 2002;62: 6667-6673.

44 Schmitt IA, Press MF. HER-2/neu gene amplification and overexpression in ductal carcinoma in situ. In: Silverstein M (ed). Ductal Carcinoma In Situ of the Breast, 2nd edn. Lippincott Williams \& Wilkins: Philadelphia, PA, 2002, pp 54-66.

45 Allred DC, Bryant J, Land S, et al. Estrogen receptor expression as a predictive marker of the effectiveness of tamoxifen in the treatment of DCIS: findings from NSABP Protocol B-24. Breast Cancer Res Treat 2002; 76:S36.

46 Carlomagno C, Perrone F, Gallo C, et al. c-erb B2 overexpression decreases the benefit of adjuvant tamoxifen in early-stage breast cancer without axillary lymph node metastases. J Clin Oncol 1996;14:2702-2708.

47 Sjogren S, Inganas M, Lindgren A, et al. Prognostic and predictive value of c-erbB-2 overexpression in primary breast cancer, alone and in combination with other prognostic markers. J Clin Oncol 1998;16:462-469.

48 Yamauchi H, Stearns V, Hayes DF. When is a tumor marker ready for prime time? A case study of c-erbB-2 as a predictive factor in breast cancer. J Clin Oncol 2001;19:2334-2356.

49 Ellis MJ, Coop A, Singh B, et al. Letrozole is more effective neoadjuvant endocrine therapy than tamoxifen for ErbB-1- and/or ErbB-2-positive, estrogen receptor-positive primary breast cancer: evidence from a phase III randomized trial. J Clin Oncol 2001; 19:3808-3816.

50 Osborne CK, Bardou V, Hopp TA, et al. Role of the estrogen receptor coactivator AIB1 (SRC-3) and HER-2/ neu in tamoxifen resistance in breast cancer. J Natl Cancer Inst 2003;95:353-361.

51 De Placido S, De Laurentiis M, Carlomagno C, et al. Twenty-year results of the Naples GUN randomized trial: predictive factors of adjuvant tamoxifen efficacy in early breast cancer. Clin Cancer Res 2003;9: 1039-1046.

52 Smith I, Dowsett M, IMPACT Trialists. Comparison of anastrazole $v s$ tamoxifen alone and in combination as neoadjuvant treatment of estrogen receptor-positive operable breast cancer in post-menopausal women: the IMPACT trial. Breast Cancer Res Treat 2003;82:S6.

53 Shou J, Massarweh S, Osborne CK, et al. Mechanisms of tamoxifen resistance: increased estrogen receptorHER2/neu cross-talk in ER/HER2-positive breast cancer. J Natl Cancer Inst 2004;96:926-935.

54 Hayes DF. Tamoxifen: Dr. Jekyll and Mr. Hyde? J Natl Cancer Inst 2004;96:895-897.

55 Lagios MD. Duct carcinoma in situ. Pathology and treatment. Surg Clin North Am 1990;70:853-871.

56 Fisher B, Dignam J, Wolmark N, et al. Lumpectomy and radiation therapy for the treatment of intraductal breast cancer: findings from National Surgical Adjuvant Breast and Bowel Project B-17. J Clin Oncol 1998; 16:441-452.

57 Berry DA, Muss HB, Thor AD, et al. HER-2/neu and p53 expression versus tamoxifen resistance in estrogen receptor-positive, node-positive breast cancer. J Clin Oncol 2000;18:3471-3479.

58 Elledge RM, Green S, Ciocca D, et al. HER-2 expression and response to tamoxifen in estrogen receptorpositive breast cancer: a Southwest Oncology Group Study. Clin Cancer Res 1998;4:7-12.

59 Jemal A, Tiwari RC, Murray T, et al. Cancer statistics, 2004. CA Cancer J Clin 2004;54:8-29. 